Удк 005.35:005.7(410)

\title{
БРИТАНСКАЯ КОНЦЕПЦИЯ КОРПОРАТИВНОГО МЕНЕДЖМЕНТА С ТОЧКИ ЗРЕНИЯ СОЦИОЛОГИЧЕСКИХ ТЕОРИЙ УПРАВЛЕНИЯ
}

\author{
Сокиркин Дмитрий Николаевич, \\ sokirkin1976@mail.ru \\ Санкт-Петербургский государственный архитектурно-строительный университет, \\ Россия, 190005, ул. 2-я Красноармейская, 4
}

Сокиркин Дмитрий Николаевич, кандидат исторических наук, доцент кафедры истории и философии Санкт-Петербургского государственного архитектурно-строительного университета.

\begin{abstract}
Актуальность исследования обусловливается значением, которое имеет эффективное корпоративное управление для деятельности компании в современных условиях. Дается обзор экономической ситуации, сложившейся в современной Великобритании, а также особенностей устройства и функционирования британского бизнеса. Исследуется влияние на политику британских корпораций такого внешнего фактора, как действующее в стране законодательство. Прослеживается связь между системой ценностей, сложившейся на протяжении длительного исторического времени в британском обществе, и системой ценностей, существующей на уровне отдельной корпорации. Рассматривается общий механизм управления, что дополняется изучением функций его отдельных участников. Сравниваются статусы и сопряженные с ними роли, выполняемые акционерами и представителями высшего менеджмента компании. Анализируется структура совета директоров. Раскрываются принципы принятия управленческих решений, степень участия в этом процессе рядовых сотрудников, а также черты личности образцового руководителя. Описываются правила и традиции социального взаимодействия в организации, а также влияние иерархического устройства британского общества на формирование системы статусов и ролей в корпорации. Затрагиваются вопросы, связанные с проблематикой повышения производительности труда, кадровой политикой, подготовкой руководящего звена, а также степенью открытости инновациям. Цель: определение и характеристика показателей эффективности корпоративного управления на примере британской концепции. Методы: социологический анализ, сравнение, обобщение и систематизация на основе теорий М. Вебера и Э. Мэйо. Результаты заключаются в раскрытии характерных черт процесса управления корпорацией в современных социально-экономических условиях, определении факторов, которые влияют на формирование управленческих решений, а также важности изучения британской концепции корпоративного менеджмента. Вывод: отмечается, что британская концепция управления корпорацией в значительной степени соответствует принципам, изложенным в рамках бюрократической теории М. Вебера и доктрины «человеческих отношений» Э. Мэйо.
\end{abstract}

Ключевые слова: Социология, управление, корпорация, Великобритания, акционеры, директора.

В современной зарубежной и отечественной научно-исследовательской литературе прослеживается возрастающий интерес к тематике корпоративного управления. Вопросы, связанные с теми или иными аспектами данной проблематики, нашли свое отражение в работах Г.В. Дружинина [1], C. Mallin [2] и В. Tricker [3], а также в некоторых коллективных публикациях [4-6]. Это обусловлено тем обстоятельством, что высокий профессиональный уровень управления в настоящее время является непременным условием для поступательного развития компании, повышения конкурентоспособности выпускаемой ей продукции или предоставляемых услуг, а также привлечения 
серьезных инвестиций. Наряду с вышеуказанным следует отметить важную роль эффективного корпоративного управления как фактора экономического и социального прогресса [7].

Непосредственным объектом изучения в рамках настоящего социологического исследования выступает британская модель корпоративного управления, достаточно широко распространенная в современном мире [8]. Нужно подчеркнуть, что указанная модель функционирует не только в Великобритании, но и в Канаде, Австралии, Новой Зеландии, ЮАР, а также, с некоторыми особенностями, в ряде других европейских стран [9].

С точки зрения современной социологии управления исследование развития британской концепции руководства корпорацией представляет серьезный интерес еще и потому, что именно Великобритания была первой европейской страной, вступившей на индустриальный путь развития. В основу этого процесса лег достаточно стремительный переход от ручного ремесленного труда к машинному производству, связанному с высоким уровнем квалификации рабочих, а также внедрением технических изобретений и технологических инноваций в промышленное производство. Серьёзнейший импульс развитию британской концепции управления дало рассмотрение А. Смитом менеджмента в качестве одного из основных элементов экономической системы капитализма. По мнению Смита, именно этот вид деятельности вносит организующее начало в производственный процесс с целью получения максимальной прибавочной стоимости [10]. В Великобритании сформировался особый подход к организации управления, стимулировавший впоследствии, по мнению основателя классической теории менеджмента П. Дракера, рост интереса к данной проблематике в других странах [11]. По мере формирования управления в качестве отдельной сферы человеческой деятельности, а также появления в рамках социальной структуры страты профессиональных управленцев, осуществлялся постепенный переход от попыток построить некую обобщающую и абстрактную теоретическую его модель к социологическому изучению реально действующих управленческих практик с целью создания концепции, максимально соответствующей реалиям современного общества.

Исследования концепций управления, сформировавшихся в отдельной стране, проводятся с учетом влияния на них таких социальных факторов, как система ценностей, особенности исторического развития, культурные традиции, социальная структура, язык, религия, воздействие культур других стран, развитие философской и научной школ [12-14]. Особенность социологии состоит в том, что она уделяет первоочередное внимание социальному аспекту управленческих отношений, рассматривая их в качестве иерархической системы и особого вида социального взаимодействия [15]. В рамках настоящего исследования будет проведен социологический анализ британской концепции управления, основанный на принципах бюрократической теории М. Вебера (18641920) и доктрины «человеческих отношений» Э. Мэйо (1880-1949).

Любую концепцию управления следует рассматривать с точки зрения эффективности самого управленческого процесса. Вначале необходимо определить суть этого понятия. Под эффективностью управления понимается уровень результативности функционирования конкретной управляющей системы, который может быть выражен в определенных показателях. Упомянутые показатели связаны как с субъектом управления (собственно управленческая деятельность), так и с его объектом (организация).

Показатели эффективности управления можно разделить на два типа:

- экономические, выявляющие соотношение результата деятельности организации и затрат на его достижение; 
- социальные, определяющие уровень социального взаимодействия в условиях организации и его влияние на экономические показатели.

В силу своей специфики социологическая наука в первую очередь делает акцент на изучение показателей социальных. Так, немецкий социолог М. Вебер полагал, что эффективность управления зависит в первую очередь от степени легитимности власти руководителя, жесткости социальной иерархии, уровня разделении труда, а также инициативности, высокой квалификации и рациональности мышления управленческих кадров, соблюдения ими действующего законодательства и установленных правил [16].

Американский социолог Э. Мэйо подчеркивал то обстоятельство, что в отдельной компании наряду с формальной структурой, в рамках которой взаимодействие сотрудников осуществляется в соответствии с официальными правилами и нормами, стихийно складывается параллельная, неформальная, структура, серьёзно влияющая на поведение персонала [17].

Для того чтобы определить, в какой мере существующая практика управления в британских корпорациях соответствует представленным выше социологическим теориям, следует предварительно проанализировать ее наиболее характерные особенности.

В рамках британской системы ценностей можно выделить индивидуалистские и материальные ориентиры, актуальные именно в контексте деловой культуры. Стремительно развивавшиеся системы капиталистических отношений и свободного рынка сформировали у представителей британского общества такие качества, как стремление проявить себя, сделать успешную карьеру и заработать серьезное состояние. В соответствии с этими взглядами ценятся, с одной стороны, такие человеческие свойства, как амбициозность, решительность, жесткость, с другой - индивидуальная ответственность и инициативность. Принято считать, что люди живут во имя работы, а не работают для того, чтобы жить. Подбор кадров происходит на основе личностных достоинств и достижений, не одобряется непотизм (прием на работу родственников). При этом прослеживается стремление избегать неопределенности и двусмысленности ситуаций. Деятельность британских компаний, как правило, жестко привязана к детально проработанным контрактам, что в определенной степени ограждает их руководство от возможности возникновения недопонимания и трений в отношениях с партнерами по бизнесу и собственными сотрудниками. Помимо индивидуализма и материализма, значительное влияние на процесс формирования главных принципов управления корпорациями непосредственно оказали особенности экономических отношений.

Одной из характерных черт британской экономики и, как следствие, концепции управления, является тенденция предоставления крупными концернами значительной степени автономии своим дочерним организациям в смысле принятия самостоятельных решений по административным, финансовым и производственным вопросам исходя из конкретной ситуации, сложившейся «на месте». Следует также отметить значительную роль, которую играют в Великобритании средний и малый бизнес. Компании указанного уровня больше подвержены риску закрытия и банкротства, соответственно, для того чтобы выстоять в жесткой конкурентной борьбе, им приходится оперативно реагировать на малейшее изменение условий внешней среды и адекватно оценивать свой внутренний потенциал [18]. Британским инвесторам присуща ориентация на получение прибыли от вложенных средств через короткий промежуток времени.

Наряду с экономическими факторами внешней среды, влияющими на деятельность британской корпорации, следует назвать юридические, а именно законодательную базу, определяющую права и обязанности акционеров, менеджмента и сотрудников организации. В рамках корпоративного законодательства Великобритании, основа 
которого была заложена в XVII-XVIII вв., особое значение имеет так называемый «Акт о компаниях» (Companies Act), принятый в 1856-1857 гг. Именно этот правовой документ законодательно оформил для британских акционерных компаний существующую по сей день двухступенчатую систему управления, состоящую из общего собрания акционеров и совета директоров [19].

Высшим органом управления корпорацией является общее собрание акционеров, правомочное решать вопросы, к числу которых относятся создание, реорганизация и, в некоторых случаях, ликвидация компании, утверждение, изменение или отмена действия учредительных документов [20]. В рамках британской традиции акционеры юридически рассматриваются как собственники акций корпорации. Они правомочны выбирать или смещать директоров, которые, являясь уполномоченными и подотчетными представителями собственников компании, фактически осуществляют управление ею.

Британская модель предполагает наличие и функционирование унитарного (однопалатного) совета директоров (Corporate Board), являющегося высшим органом управления компанией во временных промежутках между общими собраниями акционеров. На совет директоров возлагаются как исполнительные, так и надзирающие функции, к числу которых традиционно относятся: оценка стратегии корпорации, управление ее финансами, ресурсами и фондами, обеспечение соблюдения действующего законодательства, установление правил и норм поведения для служащих, проверка выполнения корпорацией её социальных обязательств.

Директора, входящие в совет, подразделяются на две категории: исполнительные и независимые (неисполнительные). Исполнительные директора - это администраторы, имеющие интересы в компании и одновременно занимающие в ней руководящие посты. Их часто называют «внутренними» директорами, или «инсайдерами» (от англ. inside - внутри). Независимые (неисполнительные) директора - приглашённые члены совета директоров, непосредственно не связанные с компанией и её менеджментом, или «аутсайдеры» (от англ. outside - снаружи). Поскольку считается, что независимые директора, в силу своего положения в компании, способны лучше защищать интересы акционеров, они должны составлять большинство по отношению к исполнительным директорам. Согласно законодательству исполнительные и независимые директора совместно несут ответственность за состояние дел в компании. При этом если исполнительные директора осуществляют непосредственное руководство повседневной деятельностью корпорации, то в задачу независимых входит оценка качества работы менеджеров. Независимые директора обладают при этом практически неограниченными правами и достаточной властью, чтобы обеспечить себе полную подотчётность менеджмента.

По действующему в Великобритании законодательству регулярность заседаний совета директоров устанавливается уставом корпорации, однако эти заседания должны проходить не менее четырёх раз в год. Они могут проводиться как в классическом, очном, формате, так и дистанционно, с помощью таких современных технических средств, как телеконференции и сеть Интернет. Как правило, кворум должен составлять не менее половины от общего числа действующих членов совета директоров.

Поскольку большинство членов советов директоров компаний непосредственно в них не работает, независимые (неисполнительные) директора при выполнении своих функций сталкиваются, с одной стороны, с проблемой дефицита времени, а с другой - с проблемой собственной некомпетентности в конкретных вопросах деятельности компании. В связи с этим, для повышения эффективности работы советов директоров в их структуре могут создаваться специальные комитеты. Для работы в комитетах могут 
привлекаться на возмездной основе независимые эксперты. В указанных комитетах рассматриваются и прорабатываются вопросы, которые затем изучаются советом. Комитеты обычно наделяются правами принимать решения от имени совета директоров в рамках установленной им компетенции, но ответственность за эти решения в полной мере несёт совет директоров. Наиболее часто при советах директоров создаются комитеты по аудиту, способствующие благоприятному для компании решению вопросов, связанных с финансовой сферой.

Еще одной особенностью советов директоров в британских корпорациях является право их членов назначать в качестве собственных заместителей так называемых «альтернативных» директоров. Смысл этой процедуры состоит в том, что альтернативный директор, в случае временного отсутствия основного директора, правомочен пользоваться всеми полномочиями последнего и исполнять его обязанности, включая участие в заседаниях совета директоров с правом решающего голоса.

Если попытаться нарисовать психологический портрет типичного британского менеджера высшего и среднего уровня, то можно представить себе целеустремленного, замкнутого и вместе с тем почтительного в отношении окружающих человека. В среде менеджеров обычно пользуются уважением уверенность в себе, убедительность, масштабность мышления и, в то же время, быстрота решений и жесткость.

Стиль принятия управленческих решений внутри британской корпорации и последующего контроля их исполнения сочетает в себе консерватизм и ориентированность на выполнение конкретных задач со значительной децентрализованностью. Современные британские менеджеры достаточно редко принимают решения единолично, предпочитая проводить консультации с подчиненными, в ходе которых допустим свободный обмен мнениями. Подобная непосредственная вовлеченность сотрудников в процесс принятия решений придает социальному взаимодействию в компании более личный характер и уменьшает формализм процесса деловой коммуникации. Наряду с этим берется на вооружение принцип «большинству людей можно доверять», что приводит к сокращению аппарата контроля и уменьшению общего количества проверок качества продукции и работы персонала. Тем не менее такие авторы, как К. Лэйн, полагают, что подобный демократизм (партисипативность) носит лишь поверхностный, напускной характер, «поскольку консультации с работниками не влияют на принятие решений» [21, с. 92]. На самом же деле образцом хорошего руководителя считается человек, оставляющий последнее слово при решении управленческих вопросов за собой, хотя при этом подчиненные могут своими советами помочь ему сделать окончательный выбор.

Ради объективности следует отметить и то обстоятельство, что партисипативная тенденция приводит к определенной девальвации самого понятия «менеджер», которым в настоящее время обозначаются специалисты самого разного профиля и руководители практически всех рангов (от начальника небольшой группы до руководителей корпорации). Кроме того, идя навстречу требованиям времени и следуя демократическим традициям, руководители не всегда отдают себе отчет в том, что среди их подчиненных есть как высокообразованные специалисты, хорошо осведомленные относительно обсуждаемых вопросов, так и менеджеры и работники, у которых отсутствует уровень образования и компетентности, необходимый для принятия серьезных управленческих решений. В результате партисипативность, практикующаяся на всех уровнях, допускает сравнение управленческих подразделений британских корпораций с деревенскими рынками, поскольку сама коммуникация и в конечном итоге принятие решений реализуются через неформальное общение. 
В действительности, хотя сама суть принимаемых решений определяется с учетом действующих формальных правил, таких как законодательство страны или распоряжения руководства организации, процесс их принятия осуществляется с использованием неформальных правил и личных связей. Это побуждает британских менеджеров заботиться о том, чтобы со временем приобрести хорошие навыки межличностного общения и способность убедить в правильности своей позиции сотрудников или партнеров по бизнесу. К коммуникационным навыкам относят не только стиль речи и манеру поведения. При первой встрече британские менеджеры, как правило, обращают внимание на манеру одеваться. Отдается предпочтение людям, носящим качественно сшитую одежду, которая при этом не являет собой последнее слово моды. Здесь проявляется определенный консерватизм британских управленческих кругов. Кроме этого, в Великобритании очень важным аспектом общей подготовки менеджеров является формирование навыков для создания и поддержания конструктивных деловых отношений с подчиненными, что создает благоприятную психологическую атмосферу в корпорации, формирует команду [22].

Одной из наиболее характерных особенностей британского общества считаются во всем мире его аристократичность и иерархичность. В качестве их определенной проекции можно рассматривать отношения «руководства-подчинения» внутри отдельной корпорации. Отношения, которые складываются между менеджерами и работниками носят неперсонифицированный и сугубо формальный характер. С одной стороны, корпоративные правила коммуникации требуют от руководителей проявлять доброжелательность по отношению к коллегам одинакового с ними ранга и к собственным подчиненным. Корпоративная культура подразумевает уважительное отношение к самой личности работника, внимание к возникающим у него проблемам, связанным с выполнением служебных обязанностей. При этом никому не следует забывать важное правило, говорящее о недопустимости совмещения сугубо деловых отношений с личными. Так, возможные попытки руководителя принять участие в делах сотрудника, не относящихся к собственно рабочему процессу, будут расценены последним как недопустимое вмешательство в его частную жизнь (privacy). С другой стороны, менеджеры склонны относить самих себя к «белым воротничкам», среднему классу, имеющему долю в собственности и контролирующему средства производства. Это дистанцирует их от остальных работников, занимающих более низкие статусные позиции в организации. Иерархичность проявляется не только в отношениях между руководителями и подчиненными, но и в том, что в одной и той же корпорации может одновременно функционировать несколько профсоюзных организаций, имеющих в Великобритании самую давнюю в мире историю и иногда конкурирующих между собой.

Насущный вопрос повышения производительности труда и, как следствие, эффективности деятельности организации решается путем разделения на этапы производственных операций, четкой организации работы и мотивации сотрудников. При этом следует отметить, что в рамках британской управленческой культуры как у рядовых сотрудников, так и у менеджеров довольно часто наблюдается отсутствие желания постоянно трудиться и делать карьеру в одной и той же организации. Нередко имеют место случаи перехода из одной компании в другую. Ввиду этого британские менеджеры не расположены уделять серьезное внимание профессиональной переподготовке и повышению квалификации работников, сопряженным с расходом времени и финансовых средств. В самой руководящей среде повышение квалификации рассматривается как менее важный показатель профессионального роста сотрудника по сравнению со скоростью его карьерного продвижения. 
Хотя при найме сотрудников работники кадровых служб компаний и непосредственно сами руководители уделяют серьезное внимание уровню образования и имеющейся репутации соискателя той или иной должности, следствием отмеченных выше настроений является снижение общего уровня квалификации британских менеджеров по сравнению, например, с их коллегами в Германии. Сами британцы считают, что именно по этой причине высшие руководящие должности во многих крупных национальных компаниях и банках занимают иностранцы.

Парадоксально, что сама по себе британская школа подготовки управленческих кадров имеет длительную историю и пользуется высоким престижем как в самой стране, так и за ее пределами. Великобритания стала лидирующей страной в Европе по степени внедрения американской модели бизнес-образования. Подобное восприятие опыта, накопленного в другой стране, нехарактерно для британцев, отличающихся своим этноцентризмом. В данном случае сыграли роль общность британской и американской культур, подразумевающие в первую очередь отсутствие языкового барьера. Ряд британских школ входят в мировую элиту бизнес-образования, а их выпускники котируются весьма высоко. Важно отметить активное участие государства в процессе подготовки управленческих кадров. В качестве примера можно указать на выделение субсидий для создания и поддержки программ МВА.

Однако на практике достаточно немногие британские менеджеры являются выпускниками ведущих университетов. С одной стороны, зачастую молодые люди, получившие высшее образование соответствующего профиля, не стремятся занять должность в корпорации, относящейся к реальному сектору экономики. С другой стороны, выпускники университетов и бизнес-школ, выбирающие деловую карьеру, как правило, редко имеют на начальном этапе профессиональную квалификацию, соответствующую профилю той организации, куда они устроились на работу. Вследствие этого Великобритания имеет самую низкую долю дипломированных специалистов среди менеджеров высшего и среднего звена по сравнению с континентальными европейскими странами - Германией и Францией. Все вышеперечисленное поставило на повестку дня вопрос о создании таких организаций, которые предоставляют действующим менеджерам возможность одновременного прохождения организационно-управленческой и узкопрофессиональной подготовки.

Помимо профессионального уровня руководящих кадров важную роль в процессе корпоративного управления играет степень открытости акционеров и высшего менеджмента компании инновациям, их ориентированность на внедрение технологических новинок и технических изобретений [23]. В этом смысле большинство британских корпораций стремятся выйти на должный уровень и впоследствии удерживаться на нем. В частности, можно отметить оптимальное приспособление технологических процессов к условиям конкретного производства, что обусловливает своевременность и оперативность модернизации последнего. При этом, наряду с вниманием к общим аспектам производственного процесса, важное значение придается нюансам и деталям. В рамках разработки концепции сложных наукоемких изделий тщательно проводятся научно-исследовательские и опытно-конструкторские работы (НИОКР) [24].

Рассмотрев особенности устройства современной британской корпорации, можно сформулировать выводы относительно соответствия существующего положения вещей отдельным принципам социологических концепций управления, предложенных М. Beбером и Э. Мэйо.

Согласно М. Веберу, одним из важнейших факторов, влияющих на эффективность управления, является легитимность власти руководителя, подразумевающая под- 
держку и доверие со стороны его подчиненных. В практике британских компаний авторитет исполнительных директоров поддерживается путем осознания персоналом самого факта их работы в компании на руководящих постах, что предполагает доскональное знакомство с положением дел на стратегическом уровне. Неисполнительные директора повышают уровень собственной компетентности путем сотрудничества с независимыми экспертами из состава специальных комитетов. Легитимность менеджеров среднего уровня основывается на партисипативном принципе принятия управленческих решений, сокращении аппарата контроля, а также традиционно присущих представителям управленческого звена британских компаний хороших коммуникативных навыках общения с подчиненными.

Жесткая иерархия, по Веберу, предполагает четкую и ясную систему статусов в организации и связанную с ней строгую субординацию. Этот принцип находит отражение в условиях британской корпорации в виде недопустимости совмещения деловых отношений с личными, дистанцирования менеджеров от рядовых работников на почве отнесения себя к среднему классу, а также разветвленной и многоступенчатой системе профсоюзов.

Веберианское требование инициативности, а также скорпулезного следования закону и предписанным правилам, предъявляемое работникам, согласуется с системой ценностей британского общества. Именно поэтому для британских корпораций характерны четкое определение функций и ответственности каждого сотрудника, а также большое значение, придаваемое силе законов, приказов и распоряжений.

Рациональное мышление управленческих кадров проявляется в инновационной открытости британских корпораций, что обуславливает оперативное и адекватное реагирование на изменение условий внешней среды и оптимальную модернизацию.

При этом ради объективности нужно подчеркнуть, что хотя М. Вебер в свое время рассматривал долгосрочную службу работника в компании как залог высокого уровня компетентности, для британских корпораций характерна высокая текучесть кадров. Кроме того, им присущ достаточно низкий, по сравнению с континентальными европейскими странами, начальный уровень образования менеджеров.

Упомянутые ранее навыки деловой коммуникации британских управленцев, проявляемые при общении с подчиненными и участие последних в обсуждении и принятии решений, являются признаками неформальной организации, открытой в свое время Э. Мэйо. Американский социолог считал наличие навыков коммуникации главным критерием отбора менеджеров, особенно низшего звена, непосредственно контактирующих с рядовыми сотрудниками. Помимо коллегиального принятия управленческих решений Э. Мэйо предлагал, в целях повышения уровня производительности труда, уделять серьезное внимание внедрению новых технологий в производственный процесс. Этим рекомендациям следуют в рамках современной политики управления компаниями в Великобритании.

Проведя таким образом социологический анализ, можно сделать вывод о том, что современной концепции управления британской корпорацией присущи как ярко выраженные черты бюрократической модели, так и признаки неформальной структуры, описанной в доктрине «человеческих отношений».

\section{СПИСОК ЛИТЕРАТУРЫ}

1. Дружинин Г.В. Сравнительно-правовые аспекты концептуальных моделей коммерческих корпораций // Сибирский юридический вестник. - 2018. - № 2 (81). - С. 116 - 122.

2. Mallin C. Corporate governance. - Oxford: Oxford University Press (OUP), 2018. - 440 p.

3. Tricker B. Corporate governance. Principles, Policies, and Practices. - Oxford: OUP, 2019. - 568 p. 
4. Ghukasyan Z.O., Aghabekian R.L., Bayanduryan G.L. Identification the quality of corporate governance concept // Quality - Access to Success. - 2018. - V. 19. - № 164. - P. 88-93.

5. Стратегический менеджмент: создание конкурентного преимущества / А. Томпсон, М. Питереф, Д. Гэмбл, А. Стрикленд. - М.: Вильямс, 2019. - 800 с.

6. Sjåfjell B., Bruner C. The Cambridge handbook of corporate law, corporate governance and sustainability. Cambridge: Cambridge University Press, 2020. - 758 p.

7. Дементьва А.Г. Современная концепция корпоративного управления // Вестник МГИМОуниверситета. - 2008. - № 2. - С. 82-88.

8. Elewechi Okike. Corporate governance in the United Kingdom // Corporate Governance in Commonwealth Countries. - UK: International Centre for Research in Accountability and Governance (CENTRAG), 2019. - P. 337-365.

9. Ключко В.Н. Англо-американская модель корпоративного управления: особенности и перспективы // Менеджмент в России и за рубежом. - 2009. - № 6. - С. 122-135.

10. Смит А. Исследования о природе и причинах богатств народов. - М.: Эксмо, 2016. - 1056 с.

11. Drucker P. The practice of management. - N.Y.: HarperCollins, 2010. -590 p.

12. Ивченко С.В. Сравнительный анализ моделей менеджмента // Экономика и менеджмент инновационных технологий. - 2017. - № 1. URL: http://ekonomika.snauka.ru/2017/01/13406 (дата обращения 10.04.2020).

13. Матненко Н.Н. Сравнительная характеристика моделей корпоративного управления // Вопросы экономики и управления. - 2019. - № 3(19). - С. 13-18.

14. Полохова Н.А. Сравнительный анализ американской, немецкой и японской моделей корпоративного управления // Молодой ученый. - 2019. - № 19 (257). - С. 160-163.

15. Тощенко Ж.Т. Социология управления: учебник и практикум для академического бакалавриата. М.: Юрайт, 2019. - 303 с.

16. Вебер М. Избранное: Образ общества. - М.; СПб.: Центр гуманитарных инициатив, 2017. - 767 с.

17. Бурганова Л.А., Савкина Е.Г. Элтон Мэйо: теоретик и практик управления. - М.: НИЦ ИНФРА-М, 2019. - 111 c.

18. Мескон М., Альберт М., Хедоури Ф. Основы менеджмента. - М.: Диалектика, 2019. - 672 с.

19. Петровичева Ю.В. Акционерное законодательство Англии и России. Сравнительно-правовой анализ. - М.: Норма, 2002. - 240 с.

20. Будылин С.Л. Новое корпоративное законодательство Великобритании: Companies Act 2006 // Coвременное право. - 2009. - № 2. - С. 102-107.

21. Lane C. Management and labour in Europe: the industrial enterprise in Germany, Britain and France. - Aldershot (U.K.): Edward Elgar, 1989. - 328 p.

22. Любицкая Е.В., Качан А.Д. Менеджмент на предприятии: американская, английская, австралийская и канадская модели управления // Colloquium-journal. - 2019. - № 3 (27). - Часть 4. - С. 13-16.

23. Бутова Т.В., Миловидова Н.А., Смирнова А.А. Особенности инновационной политики Великобритании // Международный научно-исследовательский журнал. - 2015. - № 1 (32). - Ч. 2. - С. 95-96.

24. Махортова В.К. Национальная инновационная система Великобритании // Вестник Брянского государственного университета. - 2014. - № 3. - С. 132-141.

Поступила 12.04.2020 г. 
UDC 005.35:005.7(410)

\title{
BRITISH CONCEPT OF CORPORATE GOVERNANCE: SOCIOLOGICAL ANALYSIS
}

\author{
Dmitry N. Sokirkin, \\ sokirkin1976@mail.ru
}

\begin{abstract}
Saint Petersburg State University of Architecture and Civil Engineering, 4, $2^{\text {nd }}$ Krasnoarmeyskaya street, Saint-Petersburg, 190005, Russia
\end{abstract}

Dmitry N. Sokirkin, Cand. Sc., assistant professor, Saint-Petersburg State University of Architecture and Civil Engineering.

The relevance of this research is determined by the importance of effective corporate governance for the company's activities in modern conditions. The paper introduces the overview of the economic situation in modern Britain, as well as the features of the structure and functioning of British business and examines the influence of such external factors as the current legislation on the policy of British corporations. There is a link between the value system that has been established over a long historical period in British society and the value system that exists at the level of a separate Corporation. The General mechanism of management is considered, which is supplemented by the study of the functions of its individual participants. The statuses and associated roles performed by shareholders and representatives of the company's top management are compared. The structure of the Board of Directors is analyzed. The paper reveals the principles of managerial decision-making, the degree of participation of ordinary employees in this process, as well as the personality traits of an exemplary Manager and describes the rules and traditions of social interaction in the organization, as well as the influence of the hierarchical structure of British society on the formation of a system of statuses and roles in the Corporation. The issues related to the problems of improving labor productivity, personnel policy, training of managers, as well as the degree of openness to innovation are discussed. The aim of the research is to define and characterize corporate governance performance indicators based on the example of the British concept. Methods: sociological analysis, comparison, generalization and systematization based on the theories of M. Weber and E. Mayo. The results consist in revealing the characteristic features of the corporate management in modern socio-economic conditions, determining the factors that influence the formation of management decisions, as well as the importance of studying the British concept of corporate management. As a conclusion, it is noted that the British concept of corporate governance largely corresponds to the principles set out in the framework of the bureaucratic theory of M. Weber and the doctrine of «human relations» of E. Mayo.

Key words: Sociology, management, corporation, Great Britain, shareholders, Directors.

\section{REFERENCES}

1. Druzhinin G.V. Sravnitelno-pravovye aspekty kontseptualnykh modeley kommercheskikh korporatsiy [Comparative legal aspects of conceptual models of commercial corporations]. Sibirskiy yuridicheskiy vestnik, 2018, no. 2 (81), pp. 116-122.

2. Mallin C. Corporate governance. Oxford, Oxford University Press (OUP), 2018. 440 p.

3. Tricker B. Corporate governance. Principles, Policies, and Practices. Oxford, OUP, 2019. 568 p.

4. Ghukasyan Z.O., Aghabekian R.L., Bayanduryan G.L. Identification the quality of corporate governance concept. Quality - Access to Success, 2018, no. 164, vol. 19, pp. 88-93. In Rus.

5. Tompson A., Piteref M., Gembl D., Striklend A. Strategicheskiy menedzhment: sozdanie konkurentnogo preimushchestva [Strategic management: creating a competitive advantage]. Moscow, Vilyams Publ., 2019. $800 \mathrm{p}$.

6. Sjåfjell B., Bruner C. The Cambridge handbook of corporate law, corporate governance and sustainability. Cambridge, Cambridge University Press, 2020. 758 p. 
7. Dementeva A.G. Sovremennaya kontseptsiya korporativnogo upravleniya [The modern concept of corporate governance]. Vestnik MGIMO-universiteta, 2008, no. 2, pp. 82-88.

8. Elewechi Okike. Corporate governance in the United Kingdom. Corporate governance in commonwealth countries. UK, International Centre for Research in Accountability and Governance (CENTRAG), 2019. pp. 337-365.

9. Klyuchko V.N. Anglo-amerikanskaya model korporativnogo upravleniya: osobennosti i perspektivy [The Anglo-American model of corporate governance: features and prospects]. Menedzhment v Rossii $i$ za rubezhom, 2009, no. 6, pp. 122-135.

10. Smit A. Issledovaniya o prirode i prichinakh bogatstv narodov [Studies on the nature and causes of the wealth of nations]. Moscow, Eksmo Publ., 2016. 1056 p.

11. Drucker P. The practice of management. New York, HarperCollins, 2010. 590 p.

12. Ivchenko S.V. Sravnitelny analiz modeley menedzhmenta [Comparative analysis of management models]. Ekonomika $i$ menedzhment innovatsionnykh tekhnologiy, 2017, no. 1. Available at: http://ekonomika.snauka.ru/2017/01/13406 (accessed 10 April 2020).

13. Matnenko N.N. Sravnitelnaya kharakteristika modeley korporativnogo upravleniya [Comparative characteristics of corporate governance models]. Voprosy ekonomiki i upravleniya, 2019, no. 3 (19), pp. 13-18.

14. Polokhova N.A. Sravnitelny analiz amerikanskoy, nemetskoy i yaponskoy modeley korporativnogo upravleniya [Comparative analysis of the American, German and Japanese models of corporate governance]. Molodoy ucheny, 2019, no. 19 (257), pp. 160-163.

15. Toshchenko Zh.T. Sotsiologiya upravleniya [Sociology of Management]. Moscow, Yurayt Publ., 2019. $303 \mathrm{p}$.

16. Veber M. Izbrannoe: obraz obshchestva [Favorites: the image of society]. Moscow, St. Petersburg, Tsentr gumanitarnykh initsiativ Publ., 2017. 767 p.

17. Burganova L.A., Savkina E.G. Elton Meyo: teoretik i praktik upravleniya [Elton Mayo: theorist and practitioner of management]. Moscow, NITS INFRA-M Publ., 2019. 111 p.

18. Meskon M., Albert M., Khedouri F. Osnovy menedzhmenta [Fundamentals of management]. Moscow, Dialektika Publ., 2019. 672 p.

19. Petrovicheva Yu.V. Aktsionernoe zakonodatelstvo Anglii i Rossii. Sravnitelno-pravovoy analiz [Stock legislation of England and Russia. Comparative legal analysis]. Moscow, Norma Publ., 2002. 240 p.

20. Budylin S.L. Novoe korporativnoe zakonodatelstvo Velikobritanii: Companies Act 2006 [New UK Corporate Law: Companies Act 2006]. Sovremennoe parvo, 2009, no. 2, pp. 102-107.

21. Lane C. Management and labour in Europe: the industrial enterprise in Germany, Britain and France. Aldershot (U.K.), Edward Elgar, 1989. 328 p.

22. Lyubitskaya E.V., Kachan A.D. Menedzhment na predpriyatii: amerikanskaya, angliyskaya, avstraliyskaya i kanadskaya modeli upravleniya [Enterprise management: American, English, Australian, and Canadian management models]. Colloquium-journal, 2019, no. 3, (27), P. 4, pp. 13-16.

23. Butova T.V., Milovidova N.A., Smirnova A.A. Osobennosti innovatsionnoy politiki Velikobritanii [Features of the innovation policy of the UK]. Mezhdunarodny nauchno-issledovatelskiy zhurnal, 2015, no. 1 (32), P. 2, pp. 95-96.

24. Makhortova V.K. Natsionalnaya innovatsionnaya sistema Velikobritanii [National innovation system of Great Britain]. Vestnik Bryanskogo gosudarstvennogo universiteta, 2014, no. 3, pp. 132-141.

Received: 12 April 2020. 